\title{
THE RELATIONSHIP BETWEEN RETAIL CROWDING AND CONSUMERS' SATISFACTION
}

\author{
Asta Kazakevičiūtè ${ }^{1}$, Jūratė Banyte் ${ }^{2}$ \\ ${ }^{1}$ Kaunas University of Technology, Lithuania, kazakeviciute.asta@gmail.com \\ ${ }^{2}$ Kaunas University of Technology, Lithuania, jurate.banyte@ktu.lt \\ cross ${ }^{\text {ref }} \mathrm{http} / / / \mathrm{dx}$.doi.org/10.5755/j01.em.17.2.2194
}

\begin{abstract}
One of the most important elements of social retail environment is consumers' perceived crowding, which is described as a psychological state of mind when a person's demand for space exceeds its supply. Given current population growth rates and the fact that the buying process and participation in the buying process become an expression of satisfaction with social needs, the crowding phenomenon and its studies will likely continue to be an important object of consumer behavior researches and managerial decisions.

The objective of the article is to perform a theoretical study of the crowding phenomenon in consumer behavior and to base the relationship between retail crowding and consumers' satisfaction, identifying the main mediators of this relationship.

Presented results of the empirical research reveal 3 potential mediators that should be thoroughly explored in future researches.

Keywords: perceived retail crowding, consumers' satisfaction, relationship between perceived retail crowding and consumers' satisfaction.

JEL Classification: M31.
\end{abstract}

\section{Introduction}

One of the most important elements of social retail environment is crowding perceived by consumers, which is described as a psychological state of mind when a person's demand for space exceeds its supply (Eroglu, Machleit, Barr, 2005; Vaske, Shelby, 2008; Yüksel, 2009; Jones et al. 2010; Byun, Mann 2011). Given current population growth rates and the fact that the buying process and participation in the buying process become an expression of satisfaction with social needs (Saraneva, Sääksjärvi, 2008; Vaske, Shelby, 2008), the crowding phenomenon and its studies will likely become an increasingly important object of consumer behavior researches and managerial decisions.

Retail crowding plays a major role in shaping consumer behavior, emotions, and value of the buying process. It also has a significant influence on the amount of time spent in the store, browsing behavior and consumers' satisfaction (Byun, Mann, 2011). According to Machleit, Eroglu, Mantel (2000) despite the fact that many studies have proved the existence of the relationship between retail crowding and satisfaction this relationship is not direct and is not easy to explain. On the contrary, this relationship is affected by certain mediators.

Scientific literature acknowledges the importance of emotions experienced during retail crowding and their influence on consumers' satisfaction (Machleit, Eroglu, Mantel, 2000; Eroglu, Machleit, Barr, 2005; Li, Kim, Lee, 2009; Byun, Mann, 2011). Emotions experienced by consumers are one of the most important mediators but it is still unknown what other factors or individual variables may be significant mediators in the relationship between perceived retail crowding and consumers' satisfaction.

In this context the following issues are formulated: how to explain the relationship between retail crowding and consumers' satisfaction? What factors play an important role of mediators in this relationship?

The objective of the article: to perform a theoretical study of the crowding phenomenon in consumer behavior and to base the relationship between retail crowding and consumers' satisfaction, identifying the main mediators of this relationship.

Research object: the impact of consumers' perceived retail crowding on satisfaction.

Research methods: systematic and comparative analysis of scientific literature, qualitative research employing in-depth interviews and content analysis research methods.

\section{Retail Crowding in the Consumer Behavior Theory}

Analysis of consumer behavior researches reveals that the influence of store characteristics on the consumers' decision-making process and behavior were objects of interest at the end of the $20^{\text {th }}$ century. Results of researches has shown that a physical store environment comprehensively influences consumer decisions: it influences the perceived quality of products and services, store image, amount of time and 
money spent, and store satisfaction (Harrell, Hutt, Anderson, 1980; Li, Kim, Lee, 2009). According to Yüksel (2009) and Li, Kim, Lee (2009), many previous researches were focused on the analysis of smells, colours and sounds, and their impact on consumers' behavior, but recently social environment has been taken into account more and more often.

Eroglu, Machleit, Barr (2005), Vaske, Shelby (2008), Yüksel (2009), Jones et al. (2010), Byun, Mann (2011) declare that one of the main factors of consumers' social environment is perceived retail crowding. Perceived retail crowding could be described as a feeling caused by the environment when a consumer is isolated at some level and his possibility to move is limited. It is a psychological state resulting from the situation when the user's need for space exceeds the supply and could be determined, for example, by high human density in a store or bad configuration of merchandise, shelves, and so on. crowding:

With regard to this perceived retail crowding consists of two dimensions: spatial crowding and human

- Spatial crowding refers to feelings of restricted physical body movement due to high spatial density (Li, Kim, Lee, 2009), for example, the amount of merchandise and aisles or their configuration within a store could enhance perceived spatial crowding;

- Human crowding concerns the number of other people and the extent of social interaction among them in a store.

Perceived spatial and human crowding could be understood differently, depending on individual and situational variables (Tse, Sin, Yim, 2002; Lee, Kim, Li, 2011; Baker, Wakefield, 2011):

- Shopping motives;

- Time pressure;

- Expectations of crowding;

- Prior experiences of crowding;

- Tolerance for crowding.

It was noticed that task-oriented consumers were more sensitive to retail crowding. This sensitivity is related to individual perception that crowding could prevent the accomplishment of a task. Also limited time resources cause a negative reaction to crowding - a consumer that is in a hurry and needs to buy something quickly will perceive retail crowding as high or very high.

Consumers' expectations of crowding also affect the level of perceived crowding. It is known that if a consumer has prior crowding expectations of a high level he will not be very sensitive and will experience more positive emotions. Prior experiences of crowding have a very similar effect - if previously a consumer was often shopping in stores where retail crowding was high, then retail crowding would not make a significant impact on the consumer's behavior even in a new store - the consumer is already accustomed to retail crowding. The level of personal tolerance for crowding depends on the individual demand for space. If a consumer does not need lots of space, then perceived retail crowding will not be significant.

During their research Lee, Kim, Li (2011) found out that previously discussed individual and situational variables were not significant in all retail environments. Research identified that those analyzed individual variables (except prior experiences of crowding) did not significantly impact the level of perceived retail crowding in discount stores and similar retail environments.

To sum everything up, it is necessary to note that each of individual or situational variables may cause certain emotions and affect consumers' satisfaction of the buying process. In this context it is very important to reveal the significance of emotions and their impact on the relationship between perceived retail crowding and consumers' satisfaction because satisfaction could determine a consumer's behavior in retail environment and his/her future buying intentions.

\section{The Relationship between Retail Crowding and Consumers' Satisfaction: Emotions as a Mediator}

Emotions significantly influence satisfaction and buying behavior that are formed by perceived retail crowding; they play an important role of a mediator in the relationship between retail crowding and consumers' satisfaction and could be either negative or positive.

Results of various researches reveal that the actual number of buyers in a store and their level of social interaction usually determine a higher level of tension, confusion, and undesirable outcomes for retailers such as the minimization of time spent in a store, buying less, changes of shopping plans, or even postponing shopping for next time. Despite that Byun, Mann (2011) state that perceived retail crowding also could 
impact consumers' emotions positively: due to associations a retail environment where there usually are many buyers and crowds could be considered as a popular store or a store with a good reputation. Eroglu, Machleit, Barr (2005) and Lee, Kim, Li (2011) confirm this idea and propose the idea that every consumer understands perceived retail crowding differently - it depends on individual characteristics (e.g. the personal tolerance level for crowding) or situational factors (e.g. shopping motives, amount of time that could be spent for shopping).

Moreover, it is noticed that crowding expectations are strongly influenced by the type of the store (e. g., a department store, a specialized store, a discount store) and the concept of the retailer (e. g., high-end designer stores, low-priced fast fashion stores) (Byun, Mann, 2011), that is, in discount stores, fast fashion stores, etc. a high number of consumers is expected, therefore consumers will be psychologically prepared for crowding, and crowding will not cause negative emotions. Usually some sense of competition that is felt among consumers could evoke positive emotions and increase hedonic shopping value in discount and other similar stores. It is also known that other customers affect the emotional state and behavior - if a consumer buys a product while feeling competition, then appreciable pleasure, arousal, and satisfaction are higher.

$\mathrm{Li}$, Kim, Lee (2009) analyzed the impact of emotions on the relationship between retail crowding and consumers' satisfaction (Figure 1) and found out that human crowding, pleasure, and dominance were positively related. This fact confirmed the results of previous researches, which proved that crowding did not necessarily cause only negative emotions, related to the buying process.

\section{Crowding \\ Emotion \\ Satisfaction \\ Retail Outcomes}

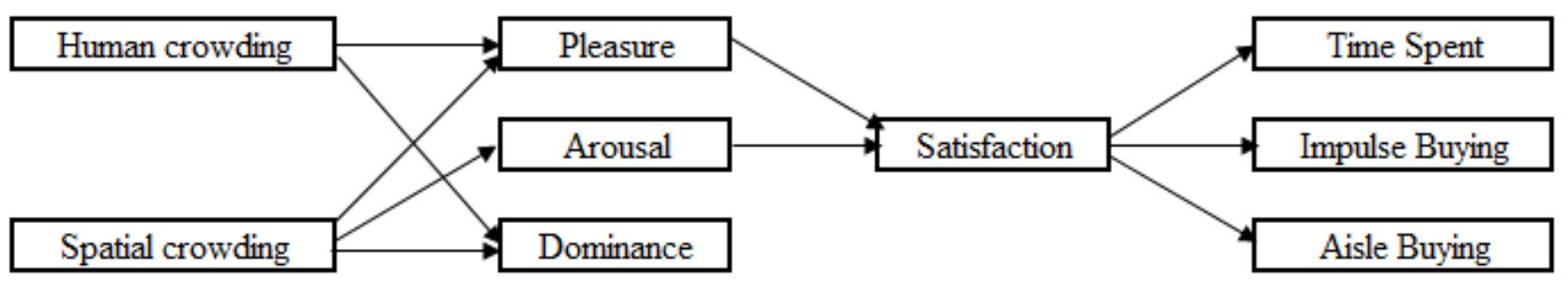

Figure 1. Relationship among crowding, emotions, satisfaction, and retail outcomes Source: Li, Kim, Lee, 2009

Figure 1 presents the research results and reveals that perceived spatial crowding is directly related to all analyzed emotions. This research proves that emotions play a mediatory role in the relationship between retail crowding and consumers' satisfaction.

Jones et al. (2010) also analyzed the importance of emotions for satisfaction. For this reason 27 emotions significant in retail environment were used in the research, they were grouped, and it was identified that all emotions had significant influence on consumers' perceived hedonic shopping value (Figure 2). Positive emotions increase shopping value, and negative emotions decrease it, but only negative emotions, such as anger, frustration, disgust, etc., are extremely important for consumers' satisfaction.

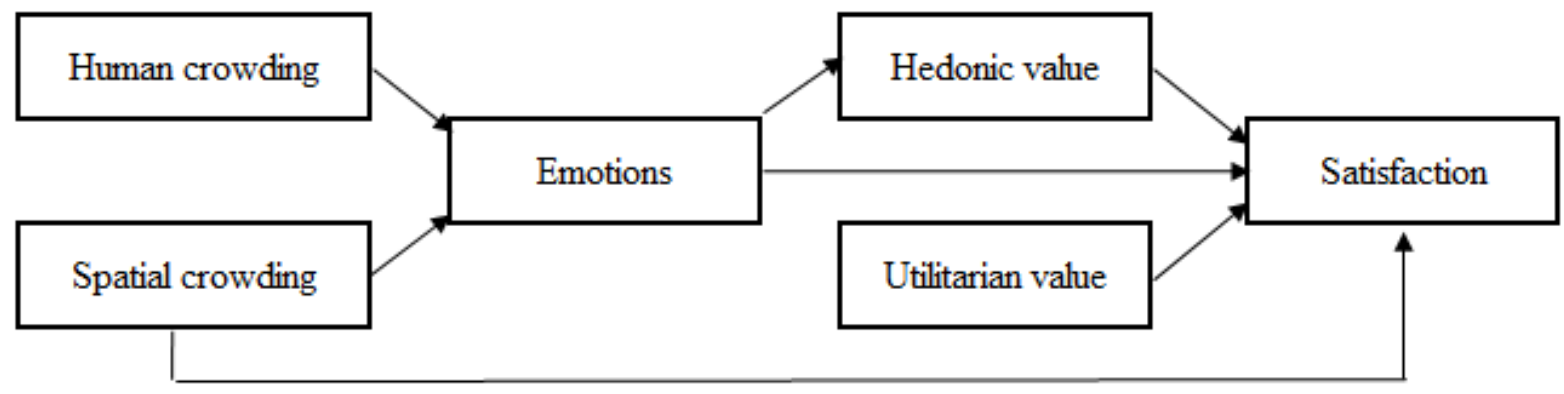

Figure 2. Relationship among crowding, emotions, values, and satisfaction Source: Jones et al., 2010

The second figure demonstrates the relationship between perceived retail crowding (human and spatial crowding) and satisfaction, where emotions as well as hedonic and utilitarian shopping values play important 
roles of mediators. Jones et al. (2010) also emphasize that crowding in stores (except discount stores and similar retail environments) may be acceptable as a possibility to be "seen" - to increase self-esteem and social status. It is also very important to remember that an empty store may cause discomfort for a consumer as much as a store that is too crowded.

Summarizing various researches, aimed at identifying the relationship between perceived retail crowding and consumers' satisfaction, it can be said that authors (Machleit, Eroglu, Mantel, 2000; Eroglu, Machleit, Barr, 2005; Li, Kim, Lee, 2009; Byun, Mann, 2011) unambiguously agree on the importance of emotions caused by crowding. It is acknowledged that consumers' emotions are one of the main mediators, and Machleit, Eroglu, Mantel (2000), Eroglu, Machleit, Barr (2005) identify the personal level of tolerance for crowding, the type of the retail store, and expectations of crowding as potential mediators in this relationship. Despite the fact that retail environment has been analyzed since the end of the $20^{\text {th }}$ century, it is still unknown if these variables really play an important mediatory role in the relationship between retail crowding and consumers' satisfaction, and what other factors or variables could be significant mediators in this relationship. This bases the necessity of empirical research in this area.

\section{Research Design}

The identification of the relationship between retail crowding and consumers' satisfaction and the factors (mediators) that have an impact on this relationship becomes increasingly important because of the significant influence on the buying process and consumers' future decisions made by satisfaction. Considering this, the relationship between retail crowding and consumer satisfaction, and the main mediators of this relationship have been identified during qualitative research. The research was performed in Kaunas; the methods of the in-depth interviews and content analysis were used.

In-depth interviews were partly structurized: interviewees were asked to imagine (or remember) themselves in realistic situations related to retail crowding. An interviewer described the situations verbally. The participants of the research were also asked to discuss their behavior and feelings during the situation and after it, to comment potential reasons and outcomes, to share previous shopping experiences and events, and to compare them to each other.

Situations were prepared using the research methodology of Machleit, Kellaris, Eroglu (1994). For example, interviewees were asked to imagine a situation when they came to a store and realized that there were much more people there than they expected, and they were asked to tell what they would do, their reaction, emotions, and the total evaluation of the shopping experience. Interviews were developed naturally, trying to discuss all possible aspects of the given situations.

In total five consumers participated in the research; the average length of an in-depth interview was 39 minutes. Sex, age, and social status were not important for the results of the research. Qualitative content analysis was carried out following the main rules applied, and text analysis was performed completing four steps, which included: 1) multiple text reading, 2) study of manifested categories through keywords, 3) subdivision of category content into subcategories, and 4) interpretation of categories and subcategories, and provision of the grounding based on the categories extracted from the text (Žydžiūnaitè, Merkys, Jonušaitė, 2004).

\section{Research Findings}

During the analysis of the in-depth interviews' transcripts repetitive elements and fragments of interviews were identified hoping to base empirically the relationship between retail crowding and consumers' satisfaction and to find out the role of mediating factors in this relationship. The main result of this analysis is the following: 4 different categories of factors were identified - emotions, disposition, time, and competition.

The first category - emotions - is presented in Table 1. This category consists of 5 subcategories: irritation, anger, disappointment, stress, and joy.

In Table 1 most of all identified emotions are negative. Stronger expressions of irritation, anger, disappointment, and stress could be related to a tendency, previously identified by Jones et al. (2010), that negative emotions remain for a longer period of time and have a bigger impact on consumers' satisfaction. Also it is noticed that situations related to spatial crowding (a bad configuration of merchandise, shelves, and so on) cause more of the negative emotions. Human crowding had a bigger impact on emotions, when there were queues in stores. Consumers' shopping satisfaction decreased after having emotionally strong and negative experiences. 
Table 1. Category - emotions

\begin{tabular}{|c|c|c|}
\hline Category & Subcategory & Confirmative statement \\
\hline \multirow{5}{*}{ Emotions } & Irritation & $\begin{array}{l}<\ldots \text { it isn't pleasant when, for example, you are looking at a product, and three } \\
\text { more eyes are looking at the same product from behind your back.>, <...I am } \\
\text { going, looking for, not finding, that irritates me...>, <but really, such things } \\
\text { usually irritate me, when you can't find everything you need in one place. }>\end{array}$ \\
\hline & Anger & $\begin{array}{l}<\text { For example, if I don't find bread in Maxima, then I won't go to Maxima, and } \\
\text { it does not matter that it is on my way. I'll go elsewhere. It is, of course, } \\
\text { sometimes anger, a similar feeling, because of the queue, when one cashier is } \\
\text { working, and there are ten empty cash desks...> }\end{array}$ \\
\hline & Disappointment & $\begin{array}{l}\text { <...for example, when you are tired after work or you don't have any time, then } \\
\text { arms droop and you say to yourself "it doesn't matter, I don't need those } \\
\text { products", you turn around and go away.> }\end{array}$ \\
\hline & Stress & $\begin{array}{l}\langle\text { You feel stress cause you are in a hurry and you don't find... }\rangle,<\ldots \text { you'll start } \\
\text { to stress how to find that thing faster and immediately inner tension grows while } \\
\text { standing in a queue }- \text { I will feel bad and probably after coming back home I will } \\
\text { feel bad because of that stressful situation. }>\end{array}$ \\
\hline & Joy & $\begin{array}{l}\text { <...then you are glad that there are no people. I could freely choose products and } \\
\text { spend more time, for example, for browsing. }>\end{array}$ \\
\hline
\end{tabular}

The only positive emotion - joy, identified during research, is related to situations when there are no people, and nobody can disturb consumers when picking wanted products or browsing in the store. This fact denies the notice of Jones et al. (2010) that an empty store could discomfort consumers as much as a store that is too crowded. According to interviewees they usually did not notice how many other consumers there were in a store except in cases when other buyers disturbed them when they were choosing a product or in similar situations.

The second category of factors that significantly impacts the evaluation of shopping and satisfaction is disposition. Disposition consists of two subcategories: disposition after a negative experience and crowding expectations (Table 2). Compared by their influence on consumers and their manifestation, these subcategories coincide with individual variables (crowding expectations and previous experience), suggested by Li, Kim, Lee (2011).

Table 2. Category - disposition

\begin{tabular}{|c|c|l|}
\hline Category & Subcategory & \multicolumn{1}{c|}{ Confirmative statement } \\
\hline \multirow{3}{*}{ Disposition } & $\begin{array}{c}\text { After a negative } \\
\text { experience }\end{array}$ & $\begin{array}{l}\text { <You try to avoid it, really. You try to observe why, and when it repeats, you } \\
\text { try to find the best alternative>, <But if at least once I felt unsatisfied, I'll } \\
\text { think before going back there.>, <after such experiences you simply try to } \\
\text { avoid these stores.> }\end{array}$ \\
\cline { 2 - 3 } & $\begin{array}{l}\text { <When you come in and suddenly there are more people than you have } \\
\text { expected and if it feels unpleasant at first I consider the necessity of shopping. } \\
\text { If it is necessary you clench your teeth and try to get something more - get } \\
\text { expectations } \\
\text { through, pass through, and go where there are less people.>, <...But if I know } \\
\text { in that store. }\end{array}$ \\
\hline
\end{tabular}

As presented in Table 2 of confirmative statements, one unpleasant situation in a store (when it is difficult to find a wanted product or when there is high density in the store) could be a sufficient argument to choose another store the next time. Consumers will come back to the same store already with strong negative expectations only when there are no other alternatives.

Expectations of human crowding also have an important impact on respondents' satisfaction consumers react more adequately, and shopping satisfaction does not decrease when they are expecting human crowds in a store, except in situations when actual human crowding is higher than it was expected in this case consumers will probably decide to come back later or even to go to another store. 
Moreover, one more important category of factors distinguished in this research was time. According to the results of the analysis of the in-depth interviews' transcripts, time has a significant direct and indirect (through emotions) impact on consumers' satisfaction in situations related to crowding (Table 3 ).

Table 3. Category - time

\begin{tabular}{|c|c|l|}
\hline Category & Subcategory & \multicolumn{1}{c|}{ Confirmative statements } \\
\hline \multirow{3}{*}{ Time } & Rush & $\begin{array}{l}\text { <I try to make it in time. When I don't - it's bad }>,<\text { I mentally count possibilities } \\
\text { to make it in time. I trample and impatiently stand in a queue.>, <When there are } \\
\text { lots of people then also there always are some uncertainties: will you make it in } \\
\text { time, do you have enough time, how much you gonna delay.> }\end{array}$ \\
\cline { 2 - 4 } & Attempt to use time & $\begin{array}{l}\text { <If I have some time and, for example, I want to use it somehow, I browse } \\
\text { through the store, then you don't pay attention to other consumers.> }\end{array}$ \\
\hline
\end{tabular}

The subcategories, presented in Table 3, (rush and attempt to use time) are cardinally different. Consumers that are in a rush react more sensitively to store environment and to all shopping obstacles - their shopping satisfaction is affected respectively. Moreover, buyers that are in a rush and confront human or spatial crowding quickly get disappointed and are willing to change the current store to an alternative that would be more comfortable.

Consumers' attempt to use their spare time could not be significantly affected by crowding, and it does not impact satisfaction of the buying process negatively: when a consumer succeeds and uses his/her spare time in the store, satisfaction of the buying process increases.

One of the situations discussed during the interviews was related to consumers' behavior and their feelings during shopping in discount stores or during seasonal sales when there was high human crowding. It was noticed that some consumers felt competition in such retail environment (Table 4).

Table 4. Category - competition

\begin{tabular}{|c|c|c|}
\hline Category & Subcategory & \multicolumn{1}{c|}{ Confirmative statements } \\
\hline Competition & Safety assurance & $\begin{array}{l}\text { <...you take and carry products that maybe you don't even need just because } \\
\text { other consumers won't buy it.>, <...you take and carry them in the store } \\
\text { (laughing) just because then others don't have a possibility to buy it. It's only } \\
\text { while I'll make a decision - if I want them or not.> }\end{array}$ \\
\hline
\end{tabular}

Confirmative statements, presented in Table 4, reveal that consumers are willing to ensure some kind of safety when facing competition. Consumers are trying to "protect" products because they do not want others to buy them. Moreover, the research also revealed that when consumers bought "protected" products they felt joy and satisfaction. Usually the impact of competition on consumers' satisfaction is not seen in ordinary stores - this category is closely related to the type of stores. The importance of the store type for the relationship between retail crowding and consumers' satisfaction has been identified by Machleit, Eroglu, Mantel (2000) and Eroglu, Machleit, Barr (2005).

In summary, during the qualitative research 4 categories of factors (emotions, disposition, time, and competition) were identified. Considering their impact on consumers' satisfaction all these categories could be treated as potential mediators of the relationship between retail crowding and satisfaction. Emotion is the only mediator of this relationship that has been previously based scientifically. It is ascertained that negative emotions have a bigger impact on satisfaction of the buying process, and they are usually caused by spatial crowding.

Moreover, disposition (negative experience and crowding expectations) is also named as a potential mediator of the analyzed relationship. It is also known that human crowding negatively affects disposition. Categories of disposition and competition factors are extremely important in specific situations - during mass sales and after a negative shopping experience. Competition factors are also closely related to the store type.

The only category of factors that has not been scientifically based as a potential mediator previously is time. It does not matter if a consumer has a limited amount of time or if he/she has some spare time - in both cases it affects the total consumers' shopping satisfaction. When consumers have very limited amount of time they react to human and spatial crowding very sensitively. Considering these facts there is a need for thorough research of the categories of disposition and competition as well as of the category of time factors that has not been previously scientifically analyzed as a potential mediator. 


\section{Conclusions}

1. After the performed analysis of scientific literature it was stated that perceived spatial and human crowding could be understood differently, and it depended on individual and situational variables shopping motives, time pressure, expectations of crowding, prior experiences of crowding, and tolerance for crowding. Also it was identified that these variables (except prior experiences of crowding) do not have a significant impact on perceived retail crowding in discount stores or other stores of this type.

2. After summarizing the results of the performed theoretical and empirical researches it is possible to declare that many studies proved the existence of the relationship between retail crowding and satisfaction but this relationship was not direct and was not easy to explain. On the contrary, this relationship is affected by certain mediators. Emotions experienced by consumers are one of the most important mediators, but it is still unknown what other factors or individual variables may be significant mediators in the relationship between perceived retail crowding and consumer satisfaction. The personal level of tolerance for crowding, store type, and expectations of crowding are identified as potential mediators of this relationship in scientific literature.

3. During qualitative research 4 categories of factors have been identified: emotions, disposition, time, and competition. These categories of factors have a particular impact on satisfaction in situations related to human or spatial crowding. The only mediator of the relationship between retail crowding and satisfaction that has been previously based scientifically are emotions.

4. After the identification of potential mediators of the relationship between retail crowding and satisfaction it is expedient to initiate further research in this area. It is necessary to thoroughly research the categories of disposition, competition, and time factors as potential mediators of this relationship.

\section{References}

1. Baker, J., \& Wakefield, K. L. (2011). How consumer shopping orientation influences perceived crowding, excitement, and stress at the mall. Journal of Academy of Marketing Science.

2. Byun, S. E., \& Mann, M. (2011). The influence of others: the impact of perceived human crowding on perceived competition, emotions, and hedonic shopping value. Clothing and Textiles Research Journal, 1-14.

3. Eroglu, S. A., Machleit, K., \& Feldman Barr, T. (2005). Perceived retail crowding and shopping satisfaction: the role of shopping values. Journal of Business Research, 58, 1146-1153.

4. Harrell, G. D., Hutt, M. D. \& Anderson, J. C. (1980). Path analysis of buyer behavior under conditions of crowding. Journal of Marketing Research, 17, 45-51.

5. Yüksel, A. (2009). Exterior color and perceived retail crowding: effects on tourists' shopping quality inferences and approach behaviors. Journal of Quality Assurance in Hospitality and Tourism, 10(4), 233-254.

6. Jones, M. Y., Vilches-Montero, S., Spence, M. T., Eroglu, S.A., \& Machleit, K. A. (2010). Do australian and american consumers differ in their perceived shopping experiences? International Journal of Retail and Distribution Management, 38(8), 578-596.

7. Lee, S. Y., Kim, J.O., \& Li, J. G. (2011). Impacts of store crowding on shopping behavior and store image. Journal of Asian Architecture and Building Engineering, 10(1), 133-140.

8. Li, J. G. T., Kim, J. O., \& Lee, S. Y. (2009). An empirical examination of perceived retail crowding, emotions, and retail outcomes. The Service Industries Journal, 29(5), 635-652.

9. Machleit, K., Eroglu, S. A., \& Mantel, S. P. (2000). Perceived retail crowding and shopping satisfaction: what modifies this relationship? Journal of Consumer Psychology, 9(1), 29-42.

10. Machleit, K., Kellaris, J. J. \& Eroglu, S. A. (1994). Human versus spatial dimensions of crowding perceptions in retail environments: a note on their measurement and effect on shopper satisfaction. Marketing Letters, 5(2), 183194.

11. Tse, A. C. B., Sin, L. \& Yim, F. H. K. (2002). How a crowded restaurant affects consumers' ${ }^{\natural}$ attribution behavior. Hospitality Management, 21, 449-454.

12. Vaske, J. J., \& Shelby, L. B. (2008). Crowding as a descriptive indicator and an evaluative standard: results from 30 years of research, Leisure Sciences, 30, 111-126.

13. Žydžiūnaitè, V., Merkys, G. \& Jonušaitè, S. (2004). Socialinio pedagogo profesinès adaptacijos kokybinè diagnostika. Pedagogika, 76, 23-33. 